\title{
OS PROCESSOS DE SALEM: UMA BREVE ANÁ- LISE DA SUA HISTORIOGRAFIA, MEMÓRIAS E REPRESENTAÇÕES
}

\section{THE SALEM WITCH TRIALS: A BRIEF ANALYSIS OF ITS HISTORIOGRAPHY, MEMORY AND REPRESENTATIONS}

Gabriela de Souza Morais ${ }^{1}$

Resumo: Esse artigo tem como objetivo apresentar reflexões acerca dos julgamentos de Salem, ocorridos entre os anos de 1692 e 1693, bem como discutir, de forma breve, algumas hipóteses apresentadas pela historiografia. Pretendemos ainda discutir esse evento como fato emblemático da cultura norte americana, como significante da e para essa cultura. Ainda, refletiremos sobre seu papel simbólico e memorialístico. Palavras-chave: Salem, historiografia, memória, representação.

Abstract: The objective of this article is to present some reflections on and make a few considerations about the Salem witch trials, which occurred between 1692-1693 as well as to discuss, briefly, some of the hypothesis presented by the historiography about the theme. We understand this event as emblematic in the North American culture, significant of and for it. Therefore, we will also discuss its symbolic and memorialistic role.

Keywords: Salem, historiography, memory, representation.

\section{Introdução}

A crença em feitiçaria e magia eram absolutamente familiares ao mundo cristão (seja ele católico ou protestante) e consequentemente aos

${ }^{1}$ Graduanda em História pela Universidade Estadual de Campinas (Unicamp). Bolsista de Iniciação Científica do CNPq sob orientação do Prof. Dr. Leandro Karnal. Contato: gsmorais25@gmail.com. 
puritanos da Nova Inglaterra. Como lembra Keith Thomas "[...] Astrologia, feitiçaria, curas pela magia, adivinhação, profecias antigas, fantasmas e duendes são hoje devidamente desdenhados por pessoas inteligentes. Mas eram levados a sério por pessoas igualmente inteligentes no passado [...]" (THOMAS, 1991: 9). Assim, tomamos a crença dessas pessoas como reais. O que, no entanto, fez os acontecimentos de 1692 e 1693 destacarem-se na história americana foi a escala e o alcance do episódio de Salem. Encontros anteriores desses colonos com bruxaria eram na maioria das vezes breves incidentes confinados a algumas pessoas em poucas comunidades. Salem, no entanto, tomou proporções inesperadas até mesmo para eles.

Essas perseguições a pessoas acusadas de bruxaria no pequeno vilarejo de Salem deixaram marcas profundas na memória dos colonos ingleses e repercutiu estrondosamente nos séculos posteriores. O tema é recorrente na historiografia, nas artes, na literatura e nos meios de comunicação. Suas interpretações adquiriram sentidos variados (embora os temas centrais e as críticas relacionadas sejam as mesmas, na maioria das vezes). Para Bernard Rosenthal:

"[...] few topics in American culture have received the broad attention received by the Salem witch Trial. The subject of scholarly tomes, films, television, shows, folklore and newspaper cartoons, and the vehicle for countless methaphors of oppression and persecution, Salem has had a powerful hold on American imagination [...]" (ROSENTHAL, 1993: 1) 


\section{Antecedentes: $o$ início da colonização}

Para entender melhor o episódio, é necessário retroceder a 1620, precisamente, a chegada dos colonos ingleses, na Nova Inglaterra. Ainda que outras experiências coloniais precedessem a colonização inglesa, esse processo foi o mais conhecido e mítico. Eram constantes as perseguições religiosas na Inglaterra nos séculos XVI e XVII, assim a América tornou-se um refúgio para muitos dos grupos perseguidos (KARNAL \& et al, 2011: 45). Um desses grupos foi o dos pilgrims (peregrinos), que além de perseguidos carregavam o ceticismo de que a Inglaterra não conseguiria livrar-se de dogmas característicos do catolicismo, e punham em dúvida sua relação com Deus. Assim, um grupo de aproximadamente 100 pessoas, deixou seu país de origem rumo ao novo continente, a América, mais especificamente na região da Vírginia a bordo do Mayflower, mas por erros, eles desembarcaram mais ao norte na costa americana, em Cape Cod.

Esses puritanos acreditavam estar construindo uma "Nova Canaã", e que eram o novo "povo de Israel". Os imigrantes da Nova Inglaterra descobriram, como menciona Bercovitch, "a América na Bíblia", já que para esses colonos a América era uma profecia, e essa terra (BERCOVITCH, 1988: 148, 149), essa promessa pertencia a eles antes deles pertencerem a terra (BERCOVITCH , 1988: 150). Como afirma Karnal eles pressupunham ser:

"(...) um grupo escolhido por Deus para criar uma sociedade de "eleitos". Em toda Bíblia procuravam as afirmativas de Deus sobre a maneira como Ele escolhia os seus e as repetiam com frequência. Tal como os hebreus no Egito, também eles foram per- 
seguidos na Inglaterra. Tal como os Hebreus, eles atravessaram o longo e tenebroso oceano, muito semelhante à travessia do deserto do Sinai. Tal como os hebreus, os puritanos receberam as indicações divinas de uma nova terra, e (...) são frequentes as referências ao "pacto" entre Deus e os colonos puritanos. A ideia de povo eleito e especial diante do mundo é uma das marcas mais fortes na constituição da cultura dos Estados Unidos." (KARNAL \& et al, 2011: 47)

Eram considerados cidadãos nessas comunidades homens adultos e membros da Igreja e, em vista de disso, podiam participar da Corte Geral. A vontade de Deus, para esses colonos constituía lei, o que podia ser entendido como teocracia, porém, os ministros da fé, não dispunham de poder direto. As questões civis eram, em geral, resolvidas pelos magistrados, que apenas quando discordavam, recorriam ao clero. Quase todos acreditavam que era dever do Estado apoiar a Igreja, cobrar comparecimento aos cultos, exigir uma moralidade, pois acreditavam que isso aumentava as possibilidades de salvação de todos os membros das comunidades (SELLERS, 1990: 26).

Tendo em vista essa estrutura, chegamos ao episódio de Salem. É importante ressaltar que em 1692, já se estava na terceira ou quarta geração dos puritanos que chegaram à América do Norte, ou seja, com recordações remotas ou relatos indiretos das perseguições sofridas por seus antepassados na Inglaterra. A fé ardente que tinha sido propulsora nos primeiros anos entre os puritanos havia diminuído. Esse contexto serve, muitas vezes como explicação para a "caça às bruxas" de Salem.

Primeiramente, é preciso lembrar que a crença em bruxas e na ação do demônio, bem como a perseguição a elas não era algo novo, era relativamente comum em todo o mundo cristão, católico ou protestante, 
e dos dois lados do oceano Atlântico, "[...] a crença num mal real e com ação efetiva era um dado social que unia desde o Rei James I (autor de um livro sobre feitiçaria) até o mais humilde camponês [...]." (KARNAL \& et al, 2011: 52). Os "Fundamentos" ou o "Código de Liberdades" ratificado em 1641 para a colônia de Massachusetts Bay previa doze crimes capitais, e entre eles estava a bruxaria, que se baseava no trecho bíblico: "Não deixarás que vivam bruxas". Assim, como lembra o historiador marxista Herbert Aptheker, "[...] a colônia estava conforme à lei de toda a Europa e, na verdade, de toda a cristandade. [...]" (APTHEKER, 1967:122). Logo, esse episódio, embora alvo de uma produção de memória gigantesca, não foi isolado.

As acusações de bruxarias começaram em fevereiro de 1692, quando meninas adolescentes ligadas ao pastor do povoado acusaram membros da comunidade de enfeitiçá-las e de possuírem pacto com o demônio. Os surtos eram frequentes: moças rolavam no chão, ficavam doentes, árvores secavam. Essas ações para os habitantes de Salem só poderiam ter ligação com ações demoníacas (KARNAL \& et al, 2011: 51). Com isso, instaurou-se um julgamento. A Igreja (como já mencionado) possuía poderes civis, Estado e Igreja, juntos, eram responsáveis pela punição e julgamento dos crimes e desobediências que ocorriam. Karnal descreve como ocorriam os julgamento:

"[... ] Alguém era acusado de feitiçaria e comparecia diante do juiz. O juiz fazia o acusado e as vítimas (as moças aflitas, como eram usualmente chamadas) ficarem frente a frente. Era comum as moças terem um novo ataque histérico diante do suposto feiticeiro. Os acusados eram enviados à prisão (...) o acusado era examinado. Havia uma crença generalizada de que a associação 
com o demônio produzia marcas no corpo: um tumor, uma mancha, regiões que não sangravam, polegar deformado. Submetidos a "tratamentos especiais", muitos réus acabavam confessando que, de fato, estavam associados ao demônio e realizavam feitiços contra a comunidade.[...]" (KARNAL \& et al, 2011: 52)

Muitas pessoas foram acusadas de bruxaria, inclusive membros politicamente influentes da comunidade. Além deles, uma escrava trazida da América Central, chamada Tituba, foi a primeira acusada pelas meninas e a primeira a confessar práticas de bruxaria, afirmando e sendo acusada de ser adepta de práticas vodu. Embora seu papel nos julgamentos pareça irrelevante, é importante lembrar que tal personagem tem um papel de destaque séculos depois na peça de Arthur Miller; e também em obras historiográficas. Um exemplo é o livro escrito por Elaine Breslaw: "Tituba, Reluctant witch of Salem.". No que tange à historiografia, há também um debate sobre se seria negra ou indígena. Toda essa comoção, no entanto, jamais poderia ter sido possível, sem as ardentes pregações de alguns pastores, como Cotton Mather ${ }^{2}$.

Os julgamentos chegaram ao fim quando as denúncias passaram a envolver pessoas politicamente influentes da colônia, tal como a esposa do governador de Massachusetts e o pastor Samuel Willard, presidente do Harvard College. Colaboraram também para o fim da perseguição, cartas, como a já mencionada escrita por Thomas Brattle e pelo próprio governador (SCHILLING, 2004: 20). Ao final dos julgamentos, quase 200 pessoas haviam sido presas. Destas, por volta de 20 delas foram

${ }^{2}$ Cotton Mather (1663-1728): Pastor nascido em Boston e escritor do livro "Maravilhas do Mundo Invisível". 
mortas, enforcadas, torturadas ou esmagadas por pedras. Inúmeras explicações foram dadas para o episódio, ou para tentar entendê-lo.

\section{Historiografia}

Um importante estudo sobre bruxaria na Nova Inglaterra foi realizado por John Putnam Demos, em seu livro Entertaining Satan, Witchcraft and the Culture of Early New England (2004). Ele trabalha com a ideia de causas sociológicas e psicológicas para o episódio, como as tensões vicinais, já que, acusar um membro da família rival de envolvimento com o demônio tinha um grande peso político: além das tensões entre mães e filhas, que enquanto possuídas, poderiam fazer coisas que não faziam normalmente, como gritar, tirar as roupas, alegando estarem enfeitiçadas pelo demônio.

Há ainda explicação de cunho biológico, como o ergotismo (doença causada por fungos presentes no centeio que causam alucinações), além de conflitos entre os puritanos e indígenas, como na Guerra do Rei Filipe (nome que os colonos deram a um líder indígena em 1675-76) que teriam deixado a comunidade em tensão permanente.

Para Herbert Aptheker, é um equivoco lançar a responsabilidade dos julgamentos nas massas, pois para ele, não foram os "muitos" que presidiram os julgamentos de bruxaria, e sim a elite que criou e constituiu o comitê de caça às feiticeiras. Ele vê no episódio de caça às bruxas, a luta de classes. Segundo ele:

"[...] Foram o aparelho governamental e o aparelho de propaganda dos dirigentes que provocaram a histeria de caça às feiticeiras 
e se esforçaram para sustentar essa histeria; e foram seus prepostos que prenderam e torturaram e executaram as feiticeiras. Foi a elite que continuou insatifeita com meras "confissões" e insistiu em que as confissões, para serem reais, deviam ser seguidas dos nome de outros agente do demônio- e que somente então aquêle que confessar poderia ser poupado à execução. Foi a elite, também, que expressou horror quando alguns dos que confessavam (...) retratavam-se. Nesses casos, foi a elite que se recusou a aceitar as retratações, considerando-as prova de aliança demoníaca e passou a executar os informantes atingidos pela crise de consciência. Na verdade, as evidencias demonstram que neste caso (...) foram a repugnância e o protesto populares que ajudaram a fazer parar os sangrentos processos.[...]" (APTHEKER, 1967:123124)

Há outros autores, como Sellers (1990), que acreditam que o surto coletivo deveu-se mais, a tensões, resultantes da mutável ordem social, econômica e política do que aos excessos do clero, embora ele reconheça que o mesmo tentou reverter a maré vazante de sua autoridade política e espiritual com lembretes ainda mais fervorosos do poder da ira de Deus (SELLERS, 1990: 31), aumentando o pânico com relação às bruxas. Ainda devemos levar em conta, como afirma Karnal,

\begin{abstract}
"[...] as frustrações dos protestantes no Novo Mundo, onde o sonho de uma comunidade perfeitamente construída de acordo com as leis de Deus e da Bíblia não havia se realizado. (...) Os habitantes de Massachussets haviam se dado conta de que não apenas a Bíblia e as boas intenções haviam atravessado o oceano, mas todas as suas mesquinharias, maledicências e tensões. Melhor seria, assim, atribuir esses problemas ao demônio e a seus seguidores.[...]" (KARNAL \& et al, 2011: 53)
\end{abstract}

É importante levar em conta, que a crença em bruxas era real no século XVII, assim como a ideia de que a moral coletiva determinava, ou aumentava a chance de salvação da comunidade. Para Schilling: 
“[...] É inquestionável que o povo acreditava sinceramente no maleficium, isto é, no dano causado pelas bruxas. Por um ou outro motivo, ele acumpliciava-se com as autoridades nas medidas tomadas para persegui-las e julgá-las. Na sociedade pré iluminista, a existência do demônio era coletivamente aceita porque servia como uma explicação conveniente para acontecimentos estranhos, para agressões injustificadas, ao que lhes parecia inusitado, ao inesperado. Por outro lado, socorrer-se de feiticeiras e de bruxas sempre foi uma maneira de tentar inflenciar pessoas ou coisas sobre as quais se tinha escasso poder. [...]" (SCHILLING, 2004:19)

$\mathrm{O}$ autor, embora reconheça a crença dessas pessoas, junta a sua análise a vertente que pensa a bruxaria e as perseguições como forma de controle social, em uma espécie de conveniência que acabou por ter contornos trágicos. No entanto, procuramos levar em conta durante nosso trabalho a interpretação de Sellers que lembra-nos que:

"[...] Com excessiva frequência, os puritanos têm sido vistos através da escura janela dos julgamentos das feiticeiras. Até bem pouco tempo, eram destacadas as tendências sombrias, repressivas, de auto-sacrifício dessas pessoas (...) embora a religiosidade dessa gente pareça extrema a uma era mais secular, os puritanos não foram necessariamente os carolas sombrios, hipócritas, da imaginação popular. Em um mundo ameaçador e inseguro, a comunidade que constituíram revelou-se imensamente atrativa para ingleses desenraizados, descontentes e, de outras maneiras, "nãoremidos" (...) Embora não fossem libertinos, com toda probabilidade não eram mais puritanos do que outros ingleses nos dois lados do Atlântico no século XVII.[...]" (SELLERS, 1990: 27)

\section{Memória e representação}

Esse episódio, como já mencionado exerce grande influência na memória e no imaginário norte americano. O eco dele ao longo do tem- 
po pode ser percebido através de obras artísticas e literárias desenvolvidas sobre o evento. Como exemplos de representações que são necessariamente fruto de uma construção de memória, podemos citar a peça de teatro "As bruxas de Salém" de 1953 do dramaturgo Arthur Miller e o filme, norte-americano, homônimo, de 1996, dirigido por Nicholas Hytner originado dessa peça. Essa recorrência dos julgamentos de Salem nos chamou a atenção. Através dessas representações tentamos entender como se deu a construção da memória desse evento, através de representações artísticas e literárias.

É preciso lembrar que ao optar-se por um episódio específico, automaticamente se excluem outros. As escolhas por uma memória "correta" sempre silencia outras, e esse silêncio não deixa também de ser uma construção. Assim, não partimos do pressuposto de que há uma memória "certa" do passado porque é impossível saber o que realmente aconteceu, já que entendemos que o passado é sempre uma construção de um diálogo entre o passado e o presente e que, como afirma Michel De Certeau "[...] uma leitura do passado, por mais controlada que seja pela análise dos documentos, é sempre dirigida por uma leitura do presente [...]" (DE CERTEAU, 2011: 11). Além disso, para Paul Ricoeur, a memória é um dos únicos modos de chegarmos ao passado, já que:

"[...] o que justifica essa preferência pela memória "certa" é a convicção de não termos outro recurso a respeito da referência ao passado, senão a própria memória. (...) Uma ambição, uma pretensão está vinculada à memória: a de ser fiel ao passado; desse ponto de vista, as deficiências procedentes do esquecimento (...) não devem ser tratadas de imediato como formas patológicas, como disfunções, mas como avesso de sombra da região ilumi- 
nada da memória, que nos liga ao que se passou antes que o transformássemos em memória. Se podemos acusar a memória de se mostrar pouco confiável, é precisamente porque ela é nosso único recurso para significar o caráter passado daquilo que declaramos lembrar. (...) Não temos nada melhor que a memória para significar algo que aconteceu, ocorreu, se passou, antes que declarássemos nos lembrar dela [...]" (RICOEUR, 2007:40).

A escolha por lembrar e representar esse episódio nos revela muito sobre a sociedade norte americana. E pensar que aspectos são revelados sobre ela com essas construções de memória foi também um dos nossos objetivos. Já que qualquer "[...] elaboração da memória se dá no presente e para responder a solicitações do presente [...]" (MENESES, 1992: 3) e que "[...] é do presente, sim, que a rememoração recebe incentivo, tanto quanto as condições para se efetivar [...]" (IDEM, IBIDEM: 3).

O debate, com relação à memória e a história são infindáveis, mas nesse artigo, procuramos trabalhar com as concepções, principalmente de Paul Ricouer e Jacques LeGoff. Acreditamos que o que sobrevive não é o conjunto daquilo que realmente existiu no passado, mas é uma escolha efetuada por alguém (LE GOFF, 1996: 509), ou seja, toda produção, seja ela historiográfica, artística ou literária, é sempre uma opção, influenciada por um contexto em que está inserida e pelas influências prévias de quem a produziu e isso caracteriza a construção de memórias do passado. Como afirma Ricouer, a Memória não é simples matriz da história, mas sim uma forma de reapropriação do passado histórico que a história instruiu (RICOEUR, 2007). Assim, optamos por trabalhar com a representação do passado como memória. Pois: 
"[...] o passado está, por assim dizer, presente na imagem como signo da sua ausência, mas trata-se de uma ausência que, não estando mais, é tida como tendo estado. Esse "tendo estado" é o que a memória se esforça por reencontrar. Ela reivindica a sua fidelidade a esse "tendo estado" [...]" (IDEM, IBIDEM).

\section{Arthur Miller e "The Crucible"}

Em 1953 Arthur Miller escreveu a peça "The Crucible", nela, ele constrói uma memória a partir da representação de Salem. Nesse ponto, partimos da teoria de Georges Duby, de que um acontecimento só existe a partir do que dizemos dele e a partir da fabricação que é feita por aqueles que a difundem (DUBY, 1993: 11,12). Ao retratar Salem, ele dialoga diretamente com as perseguições aos acusados de comunismo pelo macarthismo. Sua escolha, ao fazer essa analogia é política e consciente e, isso caracteriza uma produção de memória. O filme, de 1996 tem o roteiro inspirado na peça de $\mathrm{Miller}^{3}$, por esse motivo, optamos por analisá-los em conjunto, comparando (na medida do possível), as abordagens. Como lembra-nos Vitória Azevedo, todos os filmes (e acreditamos que essa ideia pode ser aplicada a peça de teatro) são de alguma forma históricos, pois:

"[...] nos dizem sobre a época em que foram produzidos. Desta maneira, um filme realizado na década de 30 pode ser histórico se usado como documento para estudar a década de 30, mesmo que não trate de um tema do seu passado. Mas um filme que trata de um tema do seu passado carrega um 'duplo' caráter histórico, pois além de remeter-se à história na sua temática, também pode

\footnotetext{
${ }^{3} \mathrm{O}$ autor é um dos responsáveis pelo roteiro do filme.
} 
ser usado como documento de sua época [...]" (FONSECA, 2002: 14).

Por que a escolha do episódio de Salem como metáfora? Miller ao escrever sua peça critica principalmente a intolerância norte americana, já que, para ele ela é recorrente desde as origens da república. O episódio de Salem representaria exatamente isso. Ao justificar o porquê de ter escrito a peça nesse contexto e o porquê da escolha justamente desse episódio, ele argumenta que o medo é o sentimento que está envolvido nesses dois momentos e que ele é responsável por gestos de intolerância que causam tragédias como Salem ou a perseguição dos comunistas, para ele "'The crucible' foi um ato de desespero" (MILLER, 2002:1).

Para entender porque Miller escolhe retratar Salem como metáfora de perseguição, é necessária uma breve apresentação do contexto em que o autor vivia e que a peça foi produzida.

\section{Guerra Fria e o macartismo}

Com o fim da Segunda Guerra Mundial, Estados Unidos e União Soviética passaram a disputar o poderio econômico e político do mundo, além da óbvia competição ideológica entre o capitalismo norte americano e o socialismo soviético. Essa tensão crescente acabou culminando na Guerra Fria (KARNAL \& et al, 2011: 228). O clima de tensão e desconfiança vivido entre as duas grandes potências gerou uma série de medidas internas e externas (SELLERS, 1990:365). Entre essas medidas, estava a Comissão de Atividades Antiamericanas da Câmara dos 
Deputados (HUAC, o mais duradouro dos organismos parlamentares de ação macartista).

Várias expressões foram criadas para se referir a esse momento histórico, porém o mais famoso e o que mais nos interessa nessa pesquisa é o macartismo, termo cunhado para identificar o momento histórico a partir do nome do senador Joseph (Joe) Raymond McCarthy (19081957). O termo foi utilizado para designar procedimentos de perseguição e caça aos comunistas e subversivos, atentados contra liberdade de expressão e de pensamento, intolerância ideológica, repressão política, acusações irresponsáveis e sem provas (FERREIRA, 1989: 25). O uso da expressão "caça às bruxas" (witch-hunt) para designar a repressão política nos anos 40 e 50 é uma alusão óbvia à perseguição de pessoas acusadas de bruxaria, em especial, ao episódio de Salem.

Um episódio que chamou muito a atenção do autor, e que de acordo com o mesmo, o influenciou na escrita da peça foi o chamado "os dez de Hollywood", em outubro de 1947: roteiristas, diretores, atores e escritores foram chamados a depor e tiveram suas carreiras arruinadas depois de condenados a penas variadas de seis a doze meses de cadeia pelo comitê (SCHILLING, 2004: 210).

Miller, como já mencionado, escolheu para retratar essas perseguições o episódio de Salem como metáfora. De acordo com Schilling, ao chegar à Salem, na Nova Inglaterra em 1952 e se deparar com as documentações sobre o episódio, Miller:

"[...] Espantou-se com a idêntica ausência de lógica, a mesma busca da completa abjeção das vítimas, o mesmo fanatismo, co- 
vardia e perfídia que Miller, no ano seguinte, em 1953, imortalizaria em As feiticeiras de Salem (The crucible) [...]" (IDEM, IBIDEM: 215).

\section{Análise das fontes}

A peça de Miller foi levada ao palco 1953, no auge das perseguições aos comunistas nos Estados Unidos. O autor era conhecido por levar as questões políticas e as tensões que estavam no ar e que opunham o interesse individual ao dever com a comunidade (como os princípios e patriotismo) as últimas consequências. Mas, por outro lado, seu teatro era também psicológico, com dilemas de natureza pública que apareciam plasmados nas histórias dos personagens que são geralmente "[...] imbuídos de verossimilhança quase sociológica, decerto, mas compostos com pungência e nuançamento poéticos [...]" (MILLER, 2009: 7).

Um ponto que Miller dá grande importância, e que se revela tanto na peça quanto posteriormente no filme é a delação. Mais uma vez, dialogando com seu contexto, o autor metaforiza, episódios como a delação que o colega e companheiro de trabalho Elia Kazan ${ }^{4}$ fez de seus colegas de profissão. De acordo com Schilling, esse episódio chocou Miller a tal ponto, que no dia seguinte a essa descoberta, ele se deslocou a Salem e começou a escrever essa peça (SCHILLING, 2004: 215).

Consideramos que a questão da delação exerce papel central nessa obra, pois levanta diversos questionamentos, tais como: é direito de

${ }^{4}$ Elia Kazan (1909-2003) foi um famoso diretor de teatro e cinema. Exmembro do Partido Comunista dos Estados Unidos, denunciou seus colegas ao Comitê de Investigações de Atividades Anti-Americanas. 
uma pessoa delatar outra quando se sente ameaçada? Como a sociedade reforça seus ideias de justiça quando seus valores fundamentais são colocados em cheque? Até que ponto inocentes são punidos como forma de proteger determinados valores? (CORREA: 6) . E o principal: Episódios como Salem e o macartismo são isolados ou são recorrentes em todas os períodos históricos dos Estados Unidos?

O filme, homônimo a peça e com o roteiro escrito pelo próprio Arthur Miller, foi lançado em 1996 e dirigido por Nicholas Hyther. Discussões que tratam da intolerância norte americana são recorrentes e na década de 1990 não é diferente, o tema esta mais uma vez em voga, o que torna de certa forma, as perguntas e dúvidas levantadas não só, mas também por Miller, sempre contemporâneas. Somado a esse contexto e discussão, há nessa década uma espécie de boom de filmes com a temática de bruxaria e, Salem, nada mais foi, ou significou, um "episódio real" envolvendo bruxas.

$\mathrm{O}$ filme nos importa como fonte, à medida que procuramos pensar como a história é representada nele, ou seja, não nos importa a "fidelidade histórica" porque não acreditamos que o filme ou nenhum outro documento possa exprimir uma verdade do passado, já que eles são sempre recriações. Além de não buscarmos essa interpretação fidedigna do episódio de 1692, acreditamos o filme está mais para uma recriação da peça da década de 1950 de Miller do que dos próprios julgamentos, mas inserido em outro contexto e em outro tipo de produção. Apesar de ambos serem representações artísticas de um mesmo evento histórico, a linguagem, o público, e a adaptação são diferentes, embora, muitas ve- 
zes essas diferenças do tropos literário fiquem difíceis de serem estabelecidas . É importante lembrar que o filme (e a peça), ao falarem sobre o outro (passado) dizem-nos sobre seu contexto de produção (FONSECA, 2002: 17).

O alvo principal do trabalho, que é entender como se deu a produção de memória de um episódio, também se baseia no fato de que, nenhuma memória é espontânea ou natural, tanto na peça como no filme, há um objetivo, velado ou não ao escolher exatamente Salem. Assim, nos importa a construção de discursos e a utilização da história, como se engendram os elementos históricos e personagens, omitindo uns e exaltando outros, quais os significados dados a eles, as datas e aos eventos históricos e as relações destes com o momento presente do filme (IDEM, IBIDEM: 18). Pois:

"[...] No lugar do caráter espontâneo e natural, ressaltam-se os empreendimentos deliberados de reconstrução empreendidos pela memória, que responde por via de regra a demandas e interesses políticos precisos. Toda memória é fundamentalmente "criação do passado" [...]" (BRESCIANI \& NAXARA, 2009: 41-42.

Há diferenças entre o filme e a peça, principalmente porque o contexto político e cultural é outro. Podemos, a princípio, estabelecer algumas delas, como por exemplo: um esvaziamento, em certa medida, do teor político da peça e um foco maior nas relações individuais, como a de John Proctor e Abigail Willians e os conflitos do mesmo com a esposa Elizabeth Proctor. Ou seja, há uma maior atenção no individual em detrimento do coletivo. As relações pessoais merecem tanta, ou até maior atenção no filme, do que o caos coletivo. A diferença, entre a 
peça e o filme é que enquanto a primeira quer narrar o acontecido, o segundo procura, essencialmente mostrá-lo (MILLER, 1997:12).

O interesse em torno do episódio não era de maneira nenhuma recente, mas o que acreditamos que mais chamou a atenção de Miller foi o efeito que medo e o fanatismo, quer tomados individual ou coletivamente, podem exercer nos seres humanos ou em uma comunidade. Assim, o que intrigava o autor, em Salem e no macartismo, era a prontidão com que alguns homens acusavam uns aos outros (ponto principal e recorrente em toda a peça) (CORREA: 7).

Apesar de esse texto ser exemplificador do objetivo do autor ao produzir essa peça, é possível criticar sua postura com relação ao próprio episódio. Ao construir essa memória, sua intenção é clara, como já explicado. Mas o autor desconsidera a crença religiosa que esse povoado realmente tinha em bruxas e em ações do demônio. Ele toma a interpretação psicológica, principalmente como seu argumento, como podemos também perceber na continuação do trecho anterior, em que ele se refere às paisagens mostradas no filme dialogando com o que ele chama de histeria:

\footnotetext{
"[...] Havia a possibilidade de mostrar a beleza selvagem da terra recém-cultivada, rodeada pelo mar bravo, e a total desordem e o caos das reuniões na cidade, onde as pessoas se ocupavam em condenar umas às outras à morte pela adoração ao diabo. Era possível, então, mostrar a histeria aumentando, em vez de passar a maior parte do tempo apenas relatando-a [...]" (IDEM, IBIDEM: 18).
}

A cena em que as meninas dançam com Tituba ao redor da fogueira é apenas mencionada na peça, enquanto no filme ela é logo a 
cena de abertura, nela, as meninas são flagradas pelo reverendo Samuel Parris (pai e tio de Betty e Abigail) dançando na floresta, o que desencadeia todo episódio. Acreditamos que ela é uma clara crítica ao puritanismo, que reprimiria essas meninas, e assim, seria indiretamente, uma das causas do evento. Miller argumenta um pouco diferente, para ele, a caça às bruxas não era uma consequência da adversidade do modo de vida puritano. O episódio representaria o Paraíso Perdido e a presença do demônio no vilarejo seria uma consequência da necessidade de viver a vida perfeita (e nesse ponto, o cenário do filme se torna mais que um contraponto à ação), já que a pressão constante no sentido de dedicar todo e qualquer aspecto da vida à glória de Deus é o que abre as portas para satanás, e assim a bela paisagem se tornaria um pré-requisito para a violência dos acontecimentos, pois "[...] a luz dá origem às trevas [...]" (IDEM, IBIDEM: 17-18).Várias das críticas se deslocam no espaço de tempo que separa a peça e o filme.

Um dos vários exemplos desse espaçamento temporal é o foco, que é dado no filme para as relações individuais em detrimento do caos coletivo, como a relação amorosa de Proctor e Abigail. Em várias cenas esse romance é mostrado ou insinuado. No filme, parece que a paixão que Abigail tem por John exerce maior influência no desencadear dos acontecimentos, do que a própria relação com a religião com a repressão puritana que estava bem mais evidente na peça. Abigail oscila muito, pois se pro um lado ela é culpada por iniciar a "histeria", por acusar pessoas inocentes e por ameaçar outras meninas por outro ela é apenas 
uma vítima de uma sociedade repressiva. Arthur Miller destaca isso ao comparar os dois momentos:

\begin{abstract}
"[...] Essa insistência no elo indissolúvel entre o caos comum e o drama pessoal foi para nós o ponto crucial da transformação da peça As Bruxas de Salem em um filme. Basicamente, enquanto, enquanto o teatro funciona como uma tomada de cena média permanente, um filme pode abrir a perspectiva o suficiente para abranger uma sociedade inteira e passar, em seguida, para um close capaz de revelar o sentimento de uma menina (...) a violência da multidão torna-se tanto a conseqüência como a causa da dor e da confusão através dos olhos da menina no close [...]" (IDEM, IBIDEM: 15).
\end{abstract}

Para o autor, o episódio se dá por meio de um desenrolar de fatos, onde uma coisa é consequência de um erro anterior, para ele "[...] As imagens de sucedem em uma espiral de causa e efeito que reflete com precisão o ímpeto contínuo da caça às bruxas, em que os desvios de comportamento de um indivíduo conduzem ao pânico coletivo que, por sua vez, provoca novos desvios [...]" (IDEM, IBIDEM: 15). Assim, podemos pensar se, por exemplo, o que teria causado o episódio é o adultério de Proctor, que causou as acusações desencadeadas por Abigail ou a repressão puritana, a sociedade baseada no medo como coesão social? Para Miller, sem dúvida é a segunda opção, já que Proctor representa todos os valores que o autor quer reforçar. A cena da confissão de Proctor é o ápice dos valores que Miller considera importantes, e o ponto central de sua crítica aos delatores do macartismo: Proctor prefere entregar sua vida a delatar ou desonrar seus amigos ou emprestar seu nome a mentiras e a colaborar com a continuação dos julgamentos. 
Ao optar por Salem, tanto o escritor como o diretor do filme estão, através dessas representações, construindo uma memória em torno e a partir de um fato, e como lembra Rosenthal, poucos temas na cultura americana recebem tanta atenção quanto os Julgamentos de Salem, que são de acordo com o autor, um tema poderosíssimo para ser usado como metáfora de opressão e perseguição (ROSENTHAL, 1995: 1). São justamente esses sentimentos que ambos querem reforçar em suas obras. Ao optarem por representar pessoas inocentes sendo perseguidas e mortas, eles dialogam com episódios de perseguição contemporâneos.

\section{Ponderações finais}

Por fim, procuramos entender e pensar as razões que levaram o episódio a se perpetuar ao longo dos séculos, pensando no seu significado, mas também nos motivos das representações dele derivadas e na marca profunda que ele deixou na memória dos colonos ingleses e depois na dos norte americanos. Uma ferida tão aberta e não cicatrizada que se abre a cada novo episódio de intolerância e perseguição, que de acordo com Miller, se propaga não só por toda a história americana, mas pelo mundo, pois, "[...] existem inúmeras Salems contemporâneas, prontas para anunciar bruxarias [...]" (MILLER, 1997: 16).

Neste trabalho, fruto de uma pesquisa de iniciação científica em andamento, procuramos pensar questões relativas à produção e construção de uma memória sobre um episódio emblemático da história dos Estados Unidos, e acreditamos que ele serve como um modelo de discussões e debates sobre a própria cultura desse país. O episódio abre um 
leque muito grande de possíveis pesquisas que vão desde análises do episódio até o trabalho com as suas inúmeras representações, por isso esse trabalho não chega e nem tem a pretensão de esgotar essas análises e interpretações, mas pensá-las de forma a levantar novas questões para esse debate tão amplo.

\section{Fontes}

The Crucible. In: MILLER, Arthur. The Crucible and Related Readings. Boston: McDougal Littel, 2002.

As Bruxas de Salem. Direção: Nicholas Hytner. EUA: 20th Century Fox Film Corporat, 1996. 124 min. Título original: The Crucible.

\section{Bibliografia}

APTHEKER, H. Uma nova história dos Estados Unidos: a era colonial. Rio de Janeiro: Ed. Civilização Brasileira, 1967.

BERCOVITCH, S. "A retórica como Autoridade: puritanismo, a Bíblia e o mito da América. In: Religião e Identidade Nacional. Rio de Janeiro: Graal, 1988. Tradução de Sérgio Lamarão.

BRESCIANI, S.; NAXARA, M (Org.). Memória e (RES) Sentimento. Campinas: Ed. Unicamp, 2009.

CERTEAU, Michel de. A Escrita da História. 3 edição. Rio de Janeiro: Ed. Forense Universitária, 2011.

CORREA, Lilian Cristina. As Bruxas de Salem: do teatro ao cinema. Cadernos de Pós- Graduação em letras.

DEMOS, J.P. Entertaining Satan, Witchcraft and the Culture of Early New England. Oxford University Press, 2004. 
DUBY, Georges. O domingo de Bouvines. Rio de Janeiro: Ed. Paz e Terra, 1993.

FERREIRA, Argemiro. Caça às bruxas, Macartismo: Uma tragédia Americana. Porto Alegre: L\&PM, 1989.

FONSECA. V. A. Historia imaginada no cinema : analise de Carlota Joaquina, a princesa do Brasil e Independência ou Morte. 2002. Dissertação (mestrado em história). - Universidade Estadual de Campinas.

KARNAL \& et al. História dos Estados Unidos- das origens ao século XXI. São Paulo: Ed. Contexto, 2011.

LE GOFF, Jacques. História e Memória. 4 edição. Campinas: Ed. Unicamp, 1996.

MENESES, Ulpiano Bezerra. Fontes visuais, cultura visual, História visual. Balanço provisório, propostas cautelares. Revista Brasileira de História. São Paulo, v. 23, nº 45, pp. 11-36-2003.

MILLER, Arthur. A Morte de um Caixeiro-Viajante e Outras 4 Peças. São Paulo: Ed. Companhia das Letras, 2009. . As Bruxas de Salem. Rio de Janeiro: Ed. Ediouro, 1997.

. Why I Wrote "The Crucible (online). The New Yorker, 15/04/2002, $1996 . \quad$ Disponível em: http://www.dlackey.org/weblog/docs/Why\%20I\%20Wrote\%20the\%20C rucible.pdf.

RICOUER, Paul. A memória, a História, o Esquecimento. São Paulo: Ed. UNICAMP, 2007.

ROSENTHAL, Bernard. Salem Story Reading the Witch Trials of 1692. Cambridge University Press, 1993. 
SCHILLING, Voltaire. América: A história e as contradições do império. Porto Alegre: L\&PM, 2004.

SELLERS, Charles. Uma Reavaliação da História dos Estados Unidos. Rio de Janeiro: Ed. Zahar, 1990.

SYRETT, Harold. Documentos históricos dos Estados Unidos. São Paulo: Cultrix, 1995.

THOMAS, Keith. Religião e o declínio da magia. São Paulo: Cia das Letras, 1991.

TOTA, A. P. Os americanos. São Paulo: Ed. Contexto, 2009.

Recebido em: 11/05/2014 Aceito em: 09/12/2014 